\section{In Vitro Germination of Immature Prunus lusitanica Seed}

\author{
Justin A. Schulze ${ }^{1}$, Jason D. Lattier ${ }^{2}$, and Ryan N. Contreras ${ }^{3,4}$ \\ Department of Horticulture, Oregon State University, 4017 Agricultural and \\ Life Sciences Building, Corvallis, OR 97331-7304
}

Additional index words. Portugal laurel, Portuguese cherrylaurel, tissue culture, ovule culture

\begin{abstract}
A tissue culture protocol was developed to germinate immature Prunus lusitanica seeds in vitro. The study was conducted by first identifying the best media for germination, followed by investigating effects of seed conditioning. In Expt. I, seeds were collected 12 weeks after pollination (WAP) \pm 1 week and placed on media after removing the pericarp. Eight different MS media (Murashige and Skoog, 1962) were tested (M1-M8) containing two concentrations each of 6-benzylaminopurine (BA), gibberellic acid $\left(\mathrm{GA}_{3}\right)$, and sucrose. The longest shoots resulted from M4 (1.45 $\mu \mathrm{M} \mathrm{GA}_{3}$, $6 \mu \mathrm{BA}$, and $30 \mathrm{~g} \cdot \mathrm{L}^{-1}$ sucrose), followed by $\mathrm{M1}\left(0 \mu_{M} \mathrm{GA}_{3}, 3 \mu \mathrm{MA}\right.$, and $30 \mathrm{~g} \cdot \mathrm{L}^{-1}$ sucrose). Radicle and shoot emergence was greater than or equal to $90 \%$ for M1, M3, and M4 after a stratification treatment. In Expt. II, M1 was used to test root and shoot emergence at 6, 9, and 12 WAP, with and without cold stratification. Little success was seen 6 and 9 WAP, with only callus development in 6 WAP, nonstratified seed. Cold stratification increased shoot emergence in the 12 WAP group from $4 \%$ to $28 \%$, appearing to be critical for shoot emergence. If the cotyledons are retained on the seed, future efforts to expedite breeding of $P$. lusitanica using in vitro germination should not be collected before 12 WAP and will benefit from cold stratification before germinating on M1 or M4. Chemical names: 6-benzylaminopurine (BA), gibberellic acid $\left(\mathrm{GA}_{3}\right)$.
\end{abstract}

Common cherrylaurel (Prunus laurocerasus L.) and Portuguese cherrylaurel ( $P$. lusitanica L.), collectively referred to as cherrylaurels, are highly adaptable and important ornamental species in the United States and Europe. Cherrylaurels are drought-tolerant broadleaf-evergreens commonly used in hedging. Common cherrylaurel is a mainstay in industrial and residential landscapes alike, and an important nursery crop, particularly in the Pacific northwest of the U.S. Per industry professionals; however, these popular plants have one unanimous flaw, shothole disease.

Shothole disease affects multiple stonefruit species. Symptoms present as numerous small holes in the leaves caused by fungal and/or bacterial pathogens (De Boer, 1980; Pscheidt and Ocamb, 2014; WilliamsWoodward, 1998). Infection can decrease yield in fruit crops and esthetic qualities in landscape plants. Shothole disease has plagued growers of the $P$. laurocerasus across

Received for publication 23 Mar. 2017. Accepted for publication 29 June 2017.

This article is a portion of a thesis submitted by $\mathrm{J}$. Schulze in partial fulfillment of the requirements for a M.S.

We would like to acknowledge Oregon Association of Nurseries for partial funding of this research. We also thank Carolyn Scagel, John Lambrinos, Jim Myers, Laurent Deluc, and anonymous reviewers for critical review to improve the manuscript.

${ }^{1}$ Current address: Bailey Nurseries, Inc., 1803 Antioch Church Road, Watkinsville, GA 30677.

${ }^{2}$ Graduate Research Assistant.

${ }^{3}$ Associate Professor of Horticulture.

${ }^{4}$ Corresponding author. E-mail: ryan.contreras@ oregonstate.edu. the country, a major contributing factor being that disease severity is often intensified by overhead irrigation (Dirr, 2009; WilliamsWoodward, 1998). Prunus lusitanica, by contrast, rarely expresses symptoms of shothole disease (Dirr, 2009).

Interspecific hybridization of these two species could provide a path to introgress shothole disease resistance from $P$. lusitanica into P. laurocerasus (Dirr, 2009). There have been no reports of successful hybridization of these two species, and we have not had success after more than 10,000 attempts using hand pollination. Fruit resulting from wide, interploid crosses, as in this case $[P$. laurocerasus: $2 n=22 x=176$ (Meurman, 1929), and $P$. lusitanica: $2 n=8 x=64$ (Darlington and Wylie, 1956)], often abort postfertilization (Ramsey and Schemske, 1998). One technique for recovering viable seedlings from interspecific or even intergeneric hybrids is embryo rescue.

In vitro embryo rescue has been employed in numerous genera of woody shrubs and trees including Hibiscus spp. (Van Laere et al., 2007), Prunus spp. (Kukharchyk and Kastrickaya, 2006; Liu et al., 2007), Rhododendron spp. (Eeckhaut et al., 2007), and Rosa spp. (Gudin, 1993). Liu et al. (2007) described a technique used to rescue young embryos of peach-apricot, and peach-plum hybrids. They found the highest germination percentage occurred with the cytokinin 6-benzylaminopurine (BA), in half-strength MS basal salt media (Murashige and Skoog, 1962). Kukharchyk and Kastrickaya (2006) recovered over 500 Prunus hybrids in their study, and BA performed better than other cytokinins tested. Multiple sources report chilling is required in any Prunus species to overcome physiological seed dormancy (Kukharchyk and Kastrickaya, 2006; Moore and Janick, 1983).

Prunus species exhibit intermediate physiological dormancy with a chilling requirement typically 60-90 d, and seeds that do not receive the required dormancy period have poor, if any, germination (Hartmann et al., 2011; Moore and Janick, 1983). In the case of embryo rescue, chilling requirements will likely depend on the point in development at which abortion occurs. Seeds that have intermediate physiological dormancy accumulate abscisic acid (ABA) as they develop, which triggers the onset of dormancy (Bewley, 1997). Immature seeds low in $\mathrm{ABA}$ may not require cold stratification, although dormancy period is even required for immature Prunus seeds (Kukharchyk and Kastrickaya, 2006). Cold stratification has been avoided in Prunus species by removal of the cotyledon and testa (Şan et al., 2014). However, it is unclear at what point in development that these parts are distinct enough for identification and removal.

Giberellic acid $\left(\mathrm{GA}_{3}\right)$ is a plant hormone often associated with overcoming dormancy. This hormone was used in successful in vitro germination (Şan et al., 2014) and embryo rescue (Kukharchyk and Kastrickaya, 2006) media in Prunus and could be an essential component to successful germination of immature seed. Sucrose concentration is also an important media component to be considered when performing embryo rescue, as immature embryos often require lower osmotic potential than mature embryos (Trigiano and Gray, 2011)

Once in vitro germination has occurred, seedlings often require a transfer medium to continue growth (Trigiano and Gray, 2011). The stage of root and shoot development will dictate whether an in vitro seedling can be directly transplanted or first transferred to a shoot proliferation and/or rooting media. Prior research has described effective shoot proliferation and rooting media in $P$. laurocerasus (Kalinina and Brown, 2007; Sulusoglu and Cavusoglu, 2013). We have found no information on protocols for in vitro propagation of $P$. lusitanica.

During our research to improve disease resistance of $P$. laurocerasus by attempted hybridization with $P$. lusitanica minimal and brief fruit development was observed in $P$. lusitanica as the pollen recipient (personal observation), and no fruit set has been observed in the reciprocal cross. Therefore, we focused our preliminary efforts to identify the optimal medium for germination of open-pollinated $P$. lusitanica seed. The goals of this study were to identify a tissue culture medium that would support germination of immature $P$. lusitanica seed and determine the effect of collection time and cold stratification on seedling germination without removal of the cotyledon. 


\section{Materials and Methods}

Media preparation. There were eight media combinations evaluated in this experiment (Table 1). The experiment was arranged in a completely randomized design with a three-way factorial treatment of means, including two levels of $\mathrm{GA}_{3}, \mathrm{BA}$, and sucrose. All media contained fullstrength MS basal salts and vitamins (Murashige and Skoog, 1962). In addition, all media were amended with $100 \mathrm{mg} \cdot \mathrm{L}^{-1}$ myo-inositol (Sigma-Aldrich, St. Louis, MO), $100 \mathrm{mg} \cdot \mathrm{L}^{-1}$ 4-morpholineethanesulfonic acid (MES) (Sigma-Aldrich), and $7 \mathrm{~g} \cdot \mathrm{L}^{-1}$ agar (Sigma-Aldrich). Variable rates of $\mathrm{GA}_{3}, \mathrm{BA}$, and sucrose were added to the amended MS media (Table 1); $\mathrm{GA}_{3}$ was added by filter sterilization to cooled media after autoclaving.

Before addition of the agar, all media were adjusted to $\mathrm{pH} 5.8$ using potassium hydroxide $(\mathrm{KOH})$ and hydrochloric acid (HCl). Each 150-mm culture tube was filled with $10 \mathrm{~mL}$ of the medium, capped, and then autoclaved for $25 \mathrm{~min}$ at $120{ }^{\circ} \mathrm{C}$. After the media cooled, tube caps were sealed with parafilm $\mathrm{M}^{\circledR}$ (Bemis, Neenah, WI) until the in vitro germination procedure.

Seed collection. In Expt. I (2013), openpollinated fruit were collected from one $P$. lusitanica on the Oregon State University campus (lat. $44^{\circ} 34^{\prime} 04^{\prime \prime} \mathrm{N}$, long. $123^{\circ} 17^{\prime} 14^{\prime \prime} \mathrm{W}$ ) in Corvallis, OR. Seeds were immature, and we collected just before the appearance of red color in the fruit $(\approx 12$ WAP). In Expt. II (2015), open-pollinated seeds were collected from the same tree but collection of green fruit occurred at $\approx 6$ and 9 WAP, whereas fruit at $12 \mathrm{WAP}$ were similar to those in Expt. I and were close to appearance of red/blush color. Because flowers were open-pollinated and these trees flowered for about 2 weeks, WAP was estimated \pm 1 week. Seeds are fully mature at $\approx 16$ WAP and beyond.

Seed sterilization and culture. Fruits were collected and rinsed under running water for $10 \mathrm{~min}$, moved to $70 \%$ ethanol for $30 \mathrm{~s}$, and disinfected in a $20 \%$ bleach $(1.65 \%$ sodium hypochlorite) (v/v), 2\% Polysorbate 20 (TWEEN 20; Sigma-Aldrich) (v/v) solution

Table 1. Radicle emergence, shoot emergence, and shoot length of immature (12 weeks after pollination) Prunus lusitanica seeds without testa in Expt. I. Seeds underwent 10-week cold stratification and 5 weeks under standard culture conditions in eight variations of MS (Murashige and Skoog, 1962) tissue culture medium

\begin{tabular}{|c|c|c|c|c|c|c|c|}
\hline Media & $\mathrm{GA}_{3}(\mu \mathrm{M})$ & $\mathrm{BA}(\mu \mathrm{M})$ & $\begin{array}{c}\text { Sucrose } \\
\left(\mathrm{g} \cdot \mathrm{L}^{-1}\right)\end{array}$ & $\begin{array}{c}\text { Radicle } \\
\text { emergence }(\%)\end{array}$ & $\begin{array}{c}\text { Shoot } \\
\text { emergence }(\%)\end{array}$ & $\begin{array}{l}\text { Seedlings } \\
(\text { no. })^{\mathrm{z}}\end{array}$ & $\begin{array}{c}\text { Shoot } \\
\text { length }(\mathrm{mm})^{\mathrm{y}}\end{array}$ \\
\hline$\overline{\mathrm{M} 1}$ & 0 & 3 & 30 & 100 & 90 & 27 & $34.7 \pm 2.2 \mathrm{ab}^{\mathrm{x}}$ \\
\hline M2 & 0 & 6 & 30 & 93 & 80 & 24 & $25.5 \pm 2.3 \mathrm{bc}$ \\
\hline M3 & 1.45 & 3 & 30 & 100 & 97 & 29 & $33.0 \pm 2.1 \mathrm{bc}$ \\
\hline M4 & 1.45 & 6 & 30 & 93 & 90 & 27 & $42.6 \pm 2.2 \mathrm{a}$ \\
\hline M5 & 0 & 3 & 60 & 63 & 47 & 14 & $25.5 \pm 3.0 \mathrm{bc}$ \\
\hline M6 & 0 & 6 & 60 & 47 & 33 & 10 & $26.3 \pm 3.6 \mathrm{bc}$ \\
\hline M7 & 1.45 & 3 & 60 & 70 & 60 & 18 & $27.6 \pm 2.7 \mathrm{bc}$ \\
\hline M8 & 1.45 & 6 & 60 & 80 & 70 & 21 & $22.2 \pm 2.4 \mathrm{c}$ \\
\hline
\end{tabular}

$\mathrm{GA}_{3}=$ giberellic acid; $\mathrm{BA}=6$-benzylaminopurine

${ }^{\mathrm{z}}$ Number represent seeds with emerged roots and shoot, and serves as sample sizes $(n)$ used for performing the data analysis on shoot length.

${ }^{\mathrm{y}}$ Least squared mean \pm least squared standard error of the mean.

${ }^{\mathrm{x}}$ Mean separation based on Tukey-Kramer adjusted least squared means comparison test with $P \leq 0.05$. was performed using individual media combinations (M1-M8) as the explanatory variable, and a Tukey-Kramer adjusted least squared (LS) means comparison test was applied. Radicle and shoot emergence were analyzed using logistic regression models, with $\mathrm{GA}_{3}, \mathrm{BA}$, and sucrose as the independent variables. Model parameters for radicle and shoot emergence data analyses were tested using a likelihood ratio test. In Expt. II, radicle and shoot emergence were analyzed as in Expt. I, but with WAP and cold stratification as independent variables.

\section{Results and Discussion}

Four general outcomes were seen for radicle and shoot emergence; no development, cotyledon enlargement, radicle emergence, and radicle and shoot emergence (Fig. 1). Radicle emergence was greater than $90 \%$ when cultured in M1-M4 (Table 1). Percent shoot emergence was greater than or equal to $90 \%$ in M1, M3, and M4. The longest shoot length was observed in M4 at $42.6 \mathrm{~mm}$. On average shoot length in media with $30 \mathrm{~g} \cdot \mathrm{L}^{-1}$ sucrose was greater than with $60 \mathrm{~g} \cdot \mathrm{L}^{-1}$ sucrose and $\mathrm{GA}_{3}$ had the greatest influence on shoot length at $30 \mathrm{~g} \cdot \mathrm{L}^{-1}$ than with $60 \mathrm{~g} \cdot \mathrm{L}^{-1}$ sucrose. Sucrose concentration in the media altered radicle and shoot emergence (Likelihood ratio test, $P<0.001$ ). Radicle and shoot emergence were greater on media with $30 \mathrm{~g} \cdot \mathrm{L}^{-1}$ sucrose than with $60 \mathrm{~g} \cdot \mathrm{L}^{-1}$ sucrose. $\mathrm{GA}_{3}$ also significantly increased both radicle and shoot emergence ( $P=0.03$ and $P=0.002$, respectively), but to a lesser effect.

Medium no.1 was selected as the optimized medium for Expt. II. Although $\mathrm{GA}_{3}$ increased radicle and shoot emergence on average, medium no. 1 had an equal percentage of shoot emergence and shoot length to M4. Also, M1 did not require the additional step of filter sterilizing the $\mathrm{GA}_{3}$, saving time, money, and contamination risk. When establishing a media for shoot proliferation in $P$. laurocerasus, previous research showed BA performing best between 1.0 and $3.0 \mathrm{mg} \cdot \mathrm{L}^{-1}$, without using $\mathrm{GA}_{3}$ (Sulusoglu and Cavusoglu, 2013)

In Expt. II, there was 4\% radicle emergence in the nonstratified group 6 WAP but no other radicle or shoot emergence among 6 or 9 WAP treatments (Table 2). However, the 6 WAP collection time did produce callus in two seeds in the nonstratified group. Therefore, rescuing immature seed from as early as 6 weeks may be possible with further investigation into subculturing callus in this species, and may also be necessary for successful embryo rescue.

Time of seed collection after pollination influenced radicle and shoot emergence (Likelihood ratio test, $P<0.001$ ). Cold stratification only altered shoot emergence $(P=0.02)$. The $12 \mathrm{WAP}$ groups were the only to produce shoots, and cold stratification increased the percentage of seeds in this group that produced shoots from $4 \%$ to $28 \%$. It is likely that the cold stratification helped overcome 


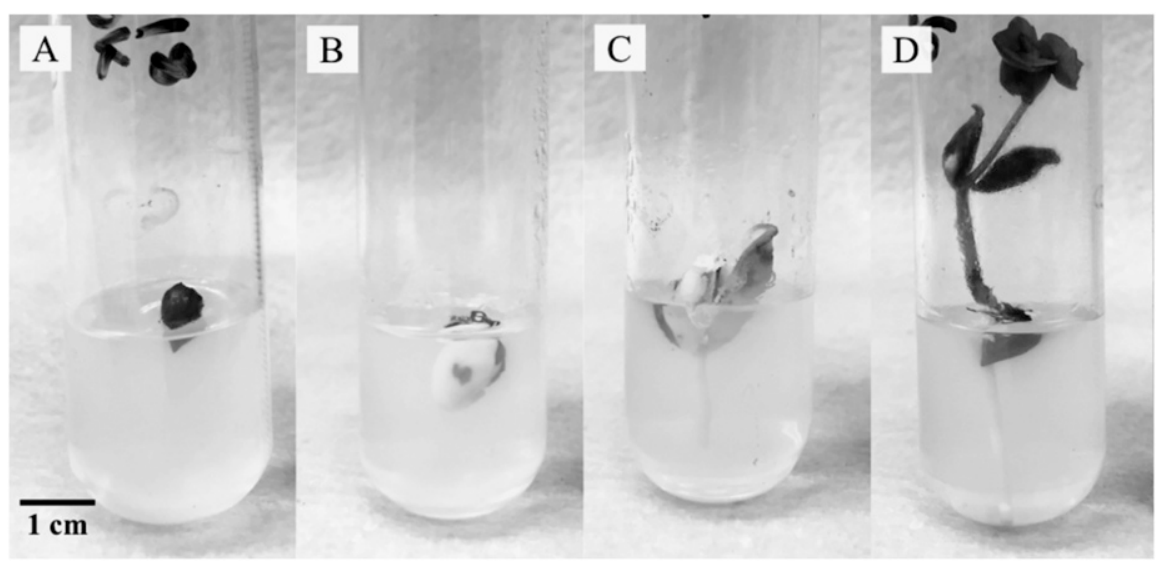

Fig. 1. Representatives of different responses observed following treatments to induce in vitro germination of cold-stratified and direct sown Prunus lusitanica collected 6, 9, and 12 weeks after pollination (WAP). (A) No development, seen in most of the 6 and 9 WAP groups, (B) cotyledon enlargement but no radicle or shoot emergence, seen in both 12 WAP groups, (C) radicle emergence with no shoot emergence, common in the $12 \mathrm{WAP}$ direct culture group, and (D) radicle and shoot emergence as seen in $28 \%$ of 12 WAP cold-stratified group.

Table 2. Radicle emergence and shoots emergence of immature Prunus lusitanica seeds with testa cultured at three different collection times in Expt. II. Seeds were evaluated with and without 10 -week cold stratification and 5 weeks under standard culture conditions.

\begin{tabular}{llcc}
\hline WAP & Culture method & Radicle emergence (\%) & Shoot emergence (\%) \\
\hline 6 & Nonstratified $^{\mathrm{y}}$ & 4 & 0 \\
6 & Cold stratified & 0 & 0 \\
9 & Nonstratified & 0 & 0 \\
9 & Cold stratified & 0 & 0 \\
12 & Nonstratified & 36 & 4 \\
12 & Cold stratified & 28 & 28 \\
\hline
\end{tabular}

${ }^{\mathrm{z}} \mathrm{WAP}=$ weeks after pollination.

${ }^{\mathrm{y}}$ Two seeds in this group produced callus.

germination inhibitors such as $\mathrm{ABA}$, allowing for shoot emergence. Sources indicate that there are likely germination inhibitors present in the cotyledon and testa in Prunus and simply removing testa increased in vitro seed germination of peach by $10 \%$ (Şan and Yildirim, 2009). Arbeloa et al. (2009) reported 60\% higher germination of Prunus cerasifera 'Myrobalan' embryos 6.5-10 mm long compared with embryos that were $0.5-2 \mathrm{~mm}$, which indicates that regardless of our seed treatment the germination likely would have remained modest in the 6 and 9 WAP collections. Although shoot emergence at 12 WAP with cold stratification was higher than the groups in Expt. II, it was noticeably lower than the results of Expt. I. We speculate that it was due to the presence of a testa on seed in Expt. II.

In Expt. I, seed development allowed for easy identification and removal of the testa. In Expt. II, 6 and 9 WAP seeds were too immature to identify and remove the testa without significant damage. In an effort to standardize our seed extraction procedure, the testa was not removed on the 12 WAP seed, diverging from the procedure in Expt. I. As seeds were observed in vitro, there was phenolic accumulation on the testa which was not present in seeds during Expt. I. Phenolics, combined with the possible presence of additional germination inhibitors, may be the cause of the decreased germination. Previous studies show mature Prunus seeds fail to germinate with intact cotyledon and testa without cold stratification; however, removal of testa from seeds showed $5 \%$ and $10 \%$ germination in apricot and peach, respectively (Şan et al., 2014). In future studies using $P$. lusitanica, perhaps removing the cotyledons completely would allow for germination without cold stratification or at earlier stages of development. Şan et al. (2014) observed dramatic increases of in vitro embryo germination without cotyledons $93 \%, 87 \%$, and $67 \%$, respectively.

Introgression of shothole disease resistance from $P$. lusitanica into common cherrylaurel will likely require culturing developing, yet highly abortive embryos in vitro to recover viable seedlings. Media developed in this study was successful in culturing immature, open-pollinated $P$. lusitanica seed at 12 WAP. The optimum germination media in this study may provide a starting place for future work on embryo rescue and in vitro germination of wide cherrylaurel hybrids.

\section{Literature Cited}

Arbeloa, A., M.E. Daorden, E. García, P. Andreu, and J.A. Martín. 2009. In vitro culture of 'Myrobalan' (Prunus cerasifera Ehrh.) em-

Bewley, J.D. 1997. Seed germination and dorof apricot, peach, and wild cherry; reaching bryos. HortScience 44:1672-1674. mancy. Plant Cell 9:1055-1066.
Darlington, C.D. and A.P. Wylie. 1956. Chromosome atlas of flowering plants. 2nd ed. Macmillian, London, United Kingdom.

De Boer, S.H. 1980. Leaf spot of cherry laurel caused by Pseudomonas syringae. Can. J. Plant Pathol. 2:235-238.

Dirr, M.A. 2009. Manual of woody landscape plants: Their identification, ornamental characteristics, culture, propagation and uses. 6th ed. Stipes Publishing, Champaign, IL.

Eeckhaut, T., E. De Keyser, J. Van Huylenbroeck, J. De Riek, and E. Van Bockstaele. 2007. Application of embryo rescue after interspecific crosses in the genus Rhododendron. Plant Cell Tissue Organ Cult. 89:29-35.

Gudin, S. 1993. Embryo rescue in Rosa hybrida L. Euphytica 72:205-212.

Hartmann, H.T., D.E. Kester, F.T. Davies, Jr., and R.L. Geneve. 2011. Hartmann and Kester's plant propagation: Principles and practices. 8th ed. Prentice Hall, Upper Saddle River, NJ.

Kalinina, A. and D.C. Brown. 2007. Micropropagation of ornamental Prunus spp. and GF305 peach, a Prunus viral indicator. Plant Cell Rep. 26:927-935.

Kukharchyk, N. and M. Kastrickaya. 2006. Embryo rescue techniques in Prunus L. breeding. J. Fruit Ornam. Plant Res. 14:129-135.

Liu, W., X. Chen, G. Liu, Q. Liang, T. He, and J. Feng. 2007. Interspecific hybridization of Prunus persica with $P$. armeniaca and $P$. salicina using embryo rescue. Plant Cell Tissue Organ Cult. 88:289-299.

Meurman, O. 1929. Prunus laurocerasus L. a species showing high polyploidy. J. Genet. 21:85-94.

Moore, J.N. and J. Janick. 1983. Methods in fruit breeding. Purdue Univ. Press, West Lafayette, IN

Murashige, T. and F. Skoog. 1962. A revised medium for rapid growth and bio assays with tobacco tissue cultures. Physiol. Plant. 15:473-497.

Pscheidt, J.W. and C.M. Ocamb (eds.). 2014. Pacific northwest plant disease management handbook. Oregon State Univ., Corvallis, OR.

Ramsey, J. and D.W. Schemske. 1998. Pathways, mechanisms, and rates of polyploid formation in flowering plants. Annu. Rev. Ecol. Syst. 29:467-501.

Şan, B. and A.N. Yildirim. 2009. Seed and in vitro embryo germination in aged almond. Seed Sci. Technol. 37:365-371.

Şan, B., A.N. Yildirim, and F. Yildirim. 2014. An in vitro germination technique for some stone fruit species: The embryo isolated from cotyledons successfully germinated without cold pre-treatment of seeds. HortScience 49:294-296.

Sulusoglu, M. and A. Cavusoglu. 2013. Micropropagation of cherry laurel (Prunus laurocerasus L.). J. Food Agr. Environ. 11:576-579.

Trigiano, R.N. and D.J. Gray (eds.). 2011. Plant tissue culture, development, and biotechnology. CRC Press, Boca Raton, FL

Van Laere, K., J.M. Van Huylenbroeck, and E. Van Bockstaele. 2007. Interspecific hybridisation between Hibiscus syriacus, Hibiscus sinosyriacus and Hibiscus paramutabilis. Euphytica 155:271-283.

Williams-Woodward, J.L. 1998. Effect of fungicide treatment to control shot-hole disease of cherry laurel. Center for Applied Nursery Research, Dearing, GA. 10 Mar. 2015. <http:// www.canr.org/98013.pdf>. 